\title{
Reorganizacija občinske uprave - primer Nove Gorice
}

UDK: 35:006:339.134

\section{Polona Kovač}

Fakulteta za upravo, Univerza v Ljubljani polona.kovac@fu.uni-lj.si

\section{Iztok Rakar}

Fakulteta za upravo, Univerza v Ljubljani iztok.rakar@fu.uni-lj.si

\section{Žiga Andoljšek}

Ministrstvo za finance

Fakulteta za upravo, Univerza v Ljubljani ziga.andoljsek@fu.uni-lj.si

\section{Barbara Grošelj}

Fakulteta za upravo, Univerza v Ljubljani barbara.groselj@fu.uni-lj.si

\section{IZVLEČEK}

Zaradi stalne potrebe po izboljšavah in racionalizaciji poslovanja se je vodstvo uprave Mestne občine Nova Gorica odločilo s pomočjo svetovalne skupine Fakultete za upravo analizirati organizacijo struktur in poslovanja mestne uprave ter ugotoviti potrebne ukrepe za racionalizacijo in večjo uspešnost. $V$ projektu so člani svetovalne skupine pristopili $k$ analizi stanja interdisciplinarno, tako da so podali pregled ekonomskih kazalnikov, primerjavo organiziranosti z drugimi mestnimi občinami, pravno analizo pristojnosti in organizacijske strukture uprave mestne občine, oceno uspešnosti po modelu CAF, analizo zadovoljstva zaposlenih ter analizo obremenjenosti oddelkov in tipičnih delovnih mest. Razvili so nekaj izvirnih metodoloških pristopov. Po analizi so identificirali vrsto možnosti za strukturne, organizacijske, menedžerske in druge izboljšave.

Ključne besede: reorganizacija, mestna občina, uprava, notranja organizacija, sistemizacija delovnih mest, CAF, analiza, racionalizacija. 


\section{Pristopi k projektu - čemu in kako?}

Fakulteta za upravo Univerze $v$ Ljubljani je izobraževalna in raziskovalna institucija, ki se ukvarja tudi z aplikativnimi projekti v različnih formalnih okvirih. Vsebina projektov sega predvsem na področja kakovosti upravnega dela, ekonomske učinkovitosti in uspešnosti delovanja javne uprave, lokalne samouprave, menedžmenta celovite kakovosti, informacijske učinkovitosti, e-uprave, edokumentov, informatizacije in e-uprave. Zaradi izkušenj se je na fakulteto konec leta 2004 obrnilo vodstvo uprave Mestne občine Nova Gorica (v nadaljevanju: MONG) ${ }^{1}$ z željo, da bi neodvisna strokovna skupina objektivno analizirala ujemanje pristojnosti, strukture, organizacije in obremenjenosti oddelkov in delovnih mest $v$ upravi z nekaj prek 80 zaposlenimi. Seveda naj bi ob ugotovitvah analize podali tudi predloge za izboljšave, tako formalne (denimo sprememba odloka o organizaciji uprave in pravilnika o sistemizaciji delovnih mest) kot tiste, ki se nanašajo na sam menedžment s poudarkom na načrtovanju in organizaciji dela. Projekt je bil po načelih raziskovalnega dela Fakultete za upravo zasnovan in usmerjen na proučevanje medsebojno povezanih vidikov, kot so upravno-pravni, javno-finančni in ekonomski ter organizacijsko-informacijski.

V Mestni občini Nova Gorica prebiva približno 36.000 ljudi. MONG je ena izmed enajstih mestnih občin $\vee$ Sloveniji s proračunom $\vee$ velikosti cca 7.7 milijard tolarjev ${ }^{2}$. $\vee$ njej deluje 22 krajevnih skupnosti, leži neposredno ob Italiji in je ena izmed redkih občin, ki niso prejemnice finančne izravnave iz državnega proračuna.

Osnovni namen projekta je bil torej racionalizacija organizacije občinske uprave oz. njenih struktur, ki naj bi se operativno izkazovala skozi čimbolj enakomerno obremenjenost zaposlenih in notranjih organizacijskih enot ter končno čimbolj učinkovito in uspešno delo uprave kot entitete lokalne skupnosti ${ }^{\mathbf{3}}$, merjeno nenazadnje prek makroekonomskih kazalnikov in primerjalno z drugimi mestnimi občinami. Poleg tega je naročnik (vodstvo mestne uprave) izrazil željo, da se ugotovi raven oz. naravnanost delovnega vzdušja oz. organizacijske klime med zaposlenimi v upravi, saj boljši medčloveški odnosi nedvomno prispevajo k uspešnejši delovni organizaciji.

1 Objavo tega prispevka in rezultatov je naročnik projekta, tj. Mestna občina Nova Gorica, odobril.

2 Od tega delež za delovanje občinske uprave obsega cca 770 milijonov tolarjev, torej desetino celotnega proračuna.

3 Občinska uprava po Zakonu o lokalni samoupravi (ZLS) nima statusa občinskega organa, vendar jo z vidika organizacije in menedžmenta tu štejemo za organizacijo. Organizacijo lahko opredelimo kot skupino ljudi, ki delujejo skupaj, da bi dosegli določen skupen cilj in $v$ ta namen razpolagajo $z$ določenimi materialnimi sredstvi. Podrobneje o različnih opredelitvah pojma v Ivanko, 2000, str. 18 in nasl. 
Kovač, Rakar, Andoljšek, Grošelj

\section{Reorganizacija občinske uprave - primer Nove Gorice}

Da bi ambiciozni cilj uresničili $v$ dogovorjenem nekajmesečnem obdobju od marca do julija 2005, smo na fakulteti oblikovali projektno skupino štirih raziskovalcev, ki so tako akademsko kot praktično strokovnjaki za različne vidike delovanja upravne organizacije. Tako smo poudarili interdisciplinarni pristop $\mathrm{k}$ analizi in oblikovanju predlogov izboljšav, ki temelji na naslednjih sklopih analiz:

- analiza ekonomskih kazalnikov - ekonomski vidik,

- pravna analiza pristojnosti in organizacijske strukture uprave mestne občine - pravni vidik,

- analiza celovite uspešnosti uprave po evropskem samoocenjevalnem modelu odličnosti za organizacije v javnem sektorju CAF (ang. Common Assessment Framework, ki temelji na modelu odličnosti EFOM) - vidik kakovosti,

- analiza zadovoljstva zaposlenih v upravi - vidik ravnanja z ljudmi pri delu (ang. Human Resource Management),

- primerjalna analiza ekonomskih kazalnikov in organiziranosti nekaterih drugih mestnih občin (Kranj, Murska Sobota, Novo mesto, Velenje) ekonomski in organizacijski vidik ter

- analiza obremenjenosti oddelkov in tipičnih delovnih mest - ekonomski in organizacijski vidik.

Ob tem naj že uvodoma poudarimo, da so bile ugotovitve na temelju različnih analiz skorajda enake, kar dokazuje njihovo legitimnost oz. upravičenost.

Potrebne informacije za analizo smo pridobivali z različnih virov, od študije strokovne literature, spletnih virov (zlasti katalog pristojnosti lokalnih skupnosti, vse o MONG in drugih mestnih občinah, pa tudi pojasnila in navodila Ministrstva RS za javno upravo ipd.), notranjih gradiv (organizacijskih aktov, proračunskih dokumentov, podatkov o poslovanju in kadrih, evidence vodenja upravnih postopkov, poročil Računskega sodišča idr.) do lastnih študij (predvsem strukturiranih intervjujev, ankete o obremenjenosti zaposlenih in ankete o njihovem zadovoljstvu).

Uvodoma je treba nadalje izpostaviti, da je občina, sploh mestna občina, svojevrsten subjekt javne uprave, ki mora delovati tako po političnih kot strokovno-upravnih ciljih in pravilih. Zato občinska uprava za razliko od državne uprave ne deluje le na bolj ali manj instrumentalni ravni izvajanja javnih politik, temveč jih prek župana kot vrha uprave kreira in izvršuje $\mathbf{4}^{\mathbf{4}}$.

4 Podrobno Šmidovnik, 1995, Virant, 1998, Vlaj, 2004, in vrsta drugih avtorjev. 


\section{Analiza stanja $z$ identifikacijo možnosti in ovir za izboljšanje}

\subsection{Analiza ekonomskih kazalnikov občine Nova Gorica}

Analiza ekonomskih kazalnikov je obsegala naslednje:

- Ekonomičnost delovanja občinske uprave izraža razmerje med odhodki občine in potrošenimi sredstvi za funkcionarje. Za primerjavo smo opazovali indeks, ki izraža razmerje med dejansko vrednostjo kazalnika in povprečno vrednostjo kazalnika. Primerljive občine pri teh kazalnikih ne beležijo takega nihanja kot MONG. Zatečeno stanje kaže, da se sredstva za funkcionarje (plače itd.) letno povečujejo, kar je potrebno podkrepiti bodisi z novimi programi, večjim obsegom del, povečanjem izobrazbene strukture bodisi s povečanim pritiskom na zaposlovanje.

- Tekoči odhodki za zaposlene kot kazalnik kaže izdatke za plače in druge izdatke zaposlenih v upravi občine na prebivalca. Primerjava kazalnika s povprečjem kaže, da kazalnik presega povprečje pri MONG za približno četrtino. Podobno raven izdatkov za zaposlene glede na povprečje beleži tudi npr. MO Koper. Tudi MO Novo mesto in MO Velenje beležita rast tekočih odhodkov za zaposlene na prebivalca v odvisnosti od povprečja.

- Prihodki in odhodki na prebivalca. Povprečna rast prihodkov znaša med leti 2000 in 2003 6,6\% in presega rast odhodkov v istem obdobju, ki znaša 4,7\%. Razlika med stopnjami rasti pri MONG znaša 1,9\% točk in je druga največja za MO Maribor. Občina tako ustvarja prihranke, s katerimi lahko tvori rezervo ali pa pokriva primanjkljaj.

Ker so kazalniki povzeti iz javne baze podatkov ${ }^{\mathbf{5}}$ in so enotni za vse občine $\checkmark$ Sloveniji, so zadržki pri interpretiranju na mestu. Predvsem posebnostim Mestne občine Nova Gorica gre pripisati dejstvo, da omenjeni kazalniki ne morejo izražati dejanskega stanja. Zato ocenjujemo, da bi bili izdatki za plače, investicije, komunalne storitve, šole in vrtce, ter socialno varnost na primerljivo osnovo primernejši kazalniki. Kot osnova so ustrezni podatki o obsegu proračuna,

5 Kazalniki po občinah, na spletni strani Službe vlade RS za lokalno samoupravo in regionalno politiko, http://www.fu.uni-lj.si/sib/vhod.asp. 
Kovač, Rakar, Andoljšek, Grošelj

Reorganizacija občinske uprave - primer Nove Gorice

površini občine, številu prebivalcev in številu zaposlenih $v$ občinski upravi. Realnejšo sliko tako dobimo šele na podlagi primerjav med primerljivimi občinami, kot so denimo Koper, Novo mesto in Velenje, z omenjenimi kazalniki.

\subsection{Primerjalna analiza organiziranosti nekaterih drugih mestnih občin}

Če si ogledamo organizacijsko strukturo nekaj mestnih občin in jo primerjamo z organizacijo $\vee$ MONG, ugotovimo, da se po različnih kazalnikih, to so zlasti število oddelkov, enakomernost porazdelitve števila zaposlenih in delovnih mest po posameznih oddelkih, število enot, ki se ukvarjajo z režijskimi nalogami idr., vse primerjano s številom zaposlenih, MONG nahaja $v$ sredini meril. Osrednji rezultat primerjave je prikazan $v$ tabeli, seveda pa je za polno sliko treba pregledati opise pristojnosti, del in nalog oddelkov ter delovnih mest.

Tabela 1: Primerjava organiziranosti v nekaterih mestnih občinah

\begin{tabular}{|l|c|c|c|c|c|}
\hline & MONG & $\begin{array}{c}\text { MO } \\
\text { Kranj }\end{array}$ & $\begin{array}{c}\text { MO Novo } \\
\text { mesto }\end{array}$ & $\begin{array}{c}\text { MO } \\
\text { Velenje }\end{array}$ & $\begin{array}{c}\text { MO } \\
\text { Murska } \\
\text { Sobota }\end{array}$ \\
\hline število zaposlenih & $81^{6}$ & 103 & 98 & 89 & 47 \\
\hline število oddelkov & 8 & 8 & 12 & 7 & 4 \\
\hline $\begin{array}{l}\text { Oddelki s splošnimi } \\
\text { službami (kabinet župana, } \\
\text { kabinet ali urad direktoria, } \\
\text { oddelek za splošne zadeve) }\end{array}$ & 3 & 1 & 4 & 1 & 1 \\
\hline $\begin{array}{l}\text { Racionalnost } \\
\text { (1 maks.) }\end{array}$ & 4 & $3 / 2$ & 5 & $2 / 3$ & 1 \\
\hline
\end{tabular}

6 Podatek glede na Pravilnik o sistemizaciji delovnih mest $v$ občinski upravi MONG št. 01504-2/2003 z dne 30. 3. 2005. 


\subsection{Pravna analiza aktov o notranji organizaciji in sistemizaciji delovnih mest na temelju funkcij mestne občine}

Ne glede na vezanost projekta na naloge in organiziranost in concreto smo $\checkmark$ svetovalni skupini menili, da je $v$ izhodišče analize smiselno postaviti stališča teorije o nalogah občin, torej funkcije in naloge in abstracto. Ta stališča smo nato primerjali z normativno določenimi nalogami in nalogami, ki se dejansko izvajajo ter na tej podlagi z uporabo ustrezne metode ugotavljanja obremenitve konkretnih delovnih mest ugotovili, ali je trenutna organiziranost primerna ali ne. Ker temelj delovanja predstavlja struktura, opredeljena $\vee$ občinskih pravnih aktih, smo analizirali tudi njihovo skladnost $z$ veljavno zakonodajo. Pravna analiza aktov o notranji organizaciji in sistemizaciji je tako pokazala nekaj manjših nepravilnosti, recimo neusklajenost sistemizacije $s$ kadrovskim načrtom in neskladje med številom sistemiziranih in dejansko zasedenih delovnih mest.

Ker občinska uprava opravlja poleg svojih nalog tudi strokovno-tehnične in druge naloge za vse organe občin, tj. za predstavniški organ, župana in nadzorni odbor ${ }^{7}$, je bilo za analizo nalog občinske uprave relevantno celotno delovno področje mestne občine, k čemur je treba prišteti tudi podporne naloge (kot so računovodstvo, kadrovska služba, pravna služba).

Glede na to, da se je projekt nanašal na mestno občino, se je pojavilo vprašanje, ali se in $v$ čem se te občine funkcionalno gledano razlikujejo od drugih občin (t. i. "navadne" občine). Pri iskanju odgovora na to vprašanje smo izhajali iz analize veljavne zakonodaje oz. Kataloga pristojnosti občin ${ }^{\mathbf{8}}$. Le-ta je poleg terminoloških pomanjkljivosti ${ }^{\mathbf{9}}$ in nejasnosti ${ }^{\mathbf{1 0}}$ pokazala, da je delokrog mestnih občin in "navadnih" občin normativno gledano skoraj identičen in da je pri samoupravnih lokalnih skupnosti poudarek na neoblastnem delovanju, tj. na servisni in pospeševalni (razvojni) funkciji, kar potrjuje stališča teorije ${ }^{11}$. To je potrdila tudi analiza proračuna MONG za leto 2005 (Proračun) in načrta razvojnih programov MONG za leta 2005-2008 (Načrt). Ker pa gre pri proračunu zgolj za seznam proračunskih postavk, ne pa za dejanski opis nalog v posameznem proračunskem letu, je bilo za pregled vrst in obsega dejansko izvajanih nalog

7 GI. npr. 32a., 33., 35. in 49. čl. ZLS.

$8 \mathrm{Na}$ spletni strani http://www.lex-localis.info/KatalogPristojnosti/SeznamMap.aspx?SectionID=999f3a8e-3a93-4cf1-a1f0-82780155d7e8.

9 Področna zakonodaja pri navajanju nalog samoupravnih lokalnih skupnosti namreč redko uporablja besedno zvezo "mestna občina" - pogosteje se uporablja beseda "mesto", kar pa pravno gledano ni pravilno.

10 Besedilo 141. člena Ustave RS, ki govori o nalogah, po katerih se mestne občine razlikujejo od "navadnih", je namreč nejasno, še posebej, če upoštevamo tudi določbe 22. in 24. člena ZLS.

11 Tako denimo Virant, 1998, str. 175. 
Kovač, Rakar, Andoljšek, Grošelj

Reorganizacija občinske uprave - primer Nove Gorice

treba preučiti, katere naloge so povezane s posamezno proračunsko postavko, katera notranja organizacijska enota je pristojna za njihovo izvedbo in kako je porazdeljen obseg nalog $v$ posameznem proračunskem letu (frekvenca nalog) ${ }^{\mathbf{1 2}}$. Smiselno enako velja tudi za načrt. Za natančnejšo ugotovitev vrst, obsega in frekvence nalog smo zato morali uporabiti druga analitična orodja. $V$ tem delu analize smo tako ugotovili le, da struktura notranjih organizacijskih enot $v$ svojem bistvu odraža poslanstvo mestnih občin, kot izhaja iz stališč teorije in analize proračuna in načrta, pri čemer pa je že na prvi pogled izstopal kabinet župana. Odprlo se je namreč vprašanje, ali je $s$ funkcionalnega in resornega zornega kota smiselno in primerno, da pokriva vse $v$ odloku določene naloge, zlasti inšpekcijski nadzor, saj gre za eno izmed ključnih represivnih in regulatornih funkcij, ki bi morala biti po našem mnenju čimbolj oddaljena od vpliva dnevne politike.

\subsection{Analiza celovite uspešnosti občinske uprave kot organizacije po evropskem modelu CAF}

Model CAF je orodje za oceno celovite uspešnosti organizacije, tako z vidika dejavnikov (voditeljstvo, strategija in načrtovanje, ravnanje z ljudmi pri delu, partnerstva in viri, procesi) kot rezultatov (za odjemalce, zaposlene, družbo in ključni finančni in nefinančni rezultati uspešnosti delovanja) ${ }^{\mathbf{1 3}}$. Model je namenjen samooceni, vendar smo se iz več razlogov odločili za eksterno oceno. Ti razlogi so bili predvsem potreba po predhodni usposobljenosti ocenjevalcev, večja objektivnost, hitrost, vprašljivost verodostojnih rezultatov pri notranjih ocenjevalcih, če je namen ocene reorganizacija ipd.. Seveda je bilo zaradi zunanje ocene treba predhodno pridobiti kopico dodatnih podatkov in opraviti vrsto strukturiranih razgovorov.

Sami rezultati ocene so bili $v$ splošnem pričakovani in se ujemajo $s$ povprečjem na slovenski ravni, pri čemer je bila najnižja vrednost med 27 podmerili $\vee$ okviru devetih dejavnikov in rezultatov zaznana pri zbiranju podatkov o potrebah udeleženih strani (ang. stakeholders) in vključevanju zaposlenih z razvijanjem dialoga in pooblaščanjem (podmerili 2.1 in 3.3). Najboljši rezultati so bili izmerjeni pri upravljanju financ in tehnologije ter rezultatih za družbo

12 Ugotovili smo sicer, da je največjo dinamiko mogoče opaziti na področju spodbujanja gospodarskega razvoja in na področju negospodarskih javnih služb (to področje je v Proračunu tudi najbolj razdelano), podobno pa je največ novih programov načrtovanih na področju infrastrukture in negospodarskih javnih služb.

13 Podrobno v Kovač, 2002, in Staes in Thijs, 2005, ter na spletnih straneh Ministrstva RS za javno upravo, http://www.mju.gov.si/index.php?id=385, in Evropskega inštituta za javno upravo, http://www.eipa.nl/default.htm. 
(podmerila 4.4, 4.5 in 8.1). Tako je projektna skupina predlagala izboljšave naslednjega:

- med cilji uprave kljub siceršnjemu zatrjevanju in delovanju vodstva MONG ni eksplicitno razvidno, ali je usmerjenost k strankam prednostna naloga ( $v$ tem mandatu župana),

- proračun nima izkazanih vsebinskih ciljev in smotrnosti,

- ne ugotavlja se zadovoljstvo strank, niti v ožjem pomenu, niti širšem (npr. vseh zavodov, katerih ustanovitelj je občina); kljub prizadevanjem na ravni informiranja občanov in drugih subjektov $v$ občini se (še) ni pristopilo h konkretizaciji participacije $v$ občini (vključevanje $v$ odločanje, tako se npr. ne objavlja predlogov odlokov pred njihovim sprejemom razen na področju prostora, kot določa področni zakon),

- $\quad$ pri ravnanju z ljudmi pri delu je treba najprej odpraviti nepravilnosti, tj. uskladitev sistemizacije s kadrovskim načrtom in izvesti ocenjevanje uradnikov; nadalje je bi bilo optimalno vzpostaviti cel model upravljanja kadrovskih virov s poudarkom na načrtnosti, sistematičnosti in uskladitvi interesov med organizacijo in posamezniki,

- sistem dokumentarnega gradiva je strogo centraliziran, z vidika povratnih informacij o delu posameznih delavcev in oddelkov je podcenjen,

- raziskati bi kazalo vzpostavljanje ustreznih okvirov za projekte in timsko delo idr.

Je pa ocena pokazala, da je vloga občine na splošno zelo ugodna pri vplivu na družbo in okolje, dobro je razvita služba za stike z javnostmi, v zvezi s kadrovskimi viri pa gre izpostaviti, da so zaposleni pripravljeni na dodatne obremenitve in odgovornosti ter da je treba nadaljevati z dobro začetimi projekti na tem področju.

\subsection{Analiza zadovoljstva zaposlenih v občinski upravi}

Za analizo zadovoljstva zaposlenih smo se $v$ projektni skupini skupaj $z$ vodstvom uprave MONG odločili med projektom, ker smo ocenili, da gre za preverjeno in učinkovito metodo, še zlasti ob uporabi vprašalnika Ministrstva RS za javno upravo ${ }^{\mathbf{1 4}}$, ki je zaradi večletne uporabe in objave rezultatov na upravnih enotah omogočil poleg vsega še primerjavo rezultatov na MONG in v

14 Vprašalnik, navodila in letno poročila za upravne enote so objavljene na spletnih staneh Ministrstva RS za javno upravo, http://www.mju.gov.si/fileadmin/mju.gov.si/pageuploads/mju dokumenti/doc/STRVPR.doc in drugi. 
Kovač, Rakar, Andoljšek, Grošelj

\section{Reorganizacija občinske uprave - primer Nove Gorice}

upravnih enotah (57 vključenih po poročilu za leto 2004 na spletnih straneh Ministrstva za javno upravo).

Pri anketi je bila z več ukrepi zagotovljena anonimnost, ki je ključna za odkritost odgovorov in $s$ tem verodostojnost rezultatov (ob vprašalnikih so bile razdeljene ovojnice, $\vee$ katere so zaposleni po izpolnitvi vprašalnike vložili in jih oddali $\vee$ zaprtih ovojnicah, ovojnice so se zbirale $\vee$ posebni skrinji, ta je bila neposredno posredovana projektni skupini fakultete $\vee$ obdelavo). $\vee$ le treh dneh smo dobili 57 izpolnjenih vprašalnikov, tj. skoraj 70\% odzivnost, ki zagotavlja statistično signifikantnost rezultatov. Po obdelavi podatkov in še posebej primerjavi z ugotovitvami zadovoljstva zaposlenih na upravnih enotah (ki so organi državne uprave, vendar prav tako kot občine delujejo na teritorialnem nivoju), ugotavljamo:

- $\quad$ med vsebinskimi sklopi je bilo najvišje ocenjeno skupinsko delo, sledita usposobljenost zaposlenih ter ustrezna oprema in organiziranost, nato nadzor nad pogoji dela in konfliktnost nalog zaposlenih ter poznavanje pričakovanj vodstva,

- najnižje je bil ocenjen sklop stimuliranje zaposlenih,

- največja odstopanja od povprečnih vrednosti oz. razpršenost odgovorov (standardni odklon) so pri trditvah oz. vprašanjih o tem, da vsak posameznik $v$ naši občinski upravi prispeva k uspehu uprave, da je ena od težav pri delu odvisnost od dela sodelavcev in o možnostih zadostnega strokovnega usposabljanja,

- zaposleni menijo, da so preobremenjeni (nekaj manj na upravnih enotah),

- $\quad$ večina meni, da imajo dovolj znanja za opravljanje del in nalog (nekaj več na upravnih enotah),

- $\quad$ okoli 70\% si ne želi spremembe delovnega mesta (enako na upravnih enotah), pri čemer tisti, ki si želijo sprememb, med drugim navajajo vzroke, da bi radi napredovali, da je delo monotono, premalo plačano ter menijo, da znajo in so sposobni več, kot od njih zahteva delo,

- velik delež (skoraj pol) meni, da je plačilo za opravljeno delo premajhno oz. ni v neposredni povezavi z učinkovitostjo,

- $\quad$ zaposleni ocenjujejo, da je včasih strokovnost nadrejena s subjektivnimi okoliščinami (nekaj manj na upravnih enotah),

- $\quad$ anketirani na upravnih enotah so kot najpomembnejši cilj v procesu dela določili zadovoljevanje potreb uporabnikov, na MONG pa obvladovanje stroškov, kjer gre omeniti, da nabor ciljev po navedbah vodstva in mnenju zaposlenih ni popolnoma skladen,

- $\quad$ več kot polovica anketiranih $(69,2 \%)$ na upravnih enotah je ponosnih na svojo zaposlitev na upravni enoti, na MONG pa kar 84\%, kar je opazno več. 
Izjemen potencial se kaže $v$ odgovorih na vprašanja, ki so povezana s cilji dela, smislom dela v občinski upravi kot javni (lokalni) organizaciji oz. s tem, ali bi zaposleni zamenjali delovno okolje in ali so ponosni, da delajo na MONG in kako se razumejo s sodelavci. Namreč kar večinski delež zaposlenih vidi poglavitni pomen lastnega dela in dela (uprave) MONG v pomoči skupnosti in sodelovanju pri njenem razvoju. Zato tudi ni presenetljivo, da lestvica motivov za delo pokaže naslednji vrstni red: 1- dobri medčloveški odnosi, 2- stopnja zahtevnosti dela, 3- pohvala in šele nato 4- plača in 5- kariera. Če povzamemo, je treba več pozornosti usmeriti k pooblaščanju in uravnoteženemu (tudi nefinančnemu) nagrajevanju zaposlenih. Sicer pa je pretežnost negativnih odgovorov vezana na politično stigmatiziranost občine in njene uprave, zlasti $\vee$ povezavi s kadrovanjem, pozitivni odgovori pa so najpogosteje pogosto vezani na altruizem in družbeno odgovornost oz. vlogo občine $v$ lokalnem družbenem okolju, med ljudmi.

\subsection{Analiza obremenjenosti oddelkov in tipičnih delov- nih mest}

$\checkmark$ kolikor želimo povečati učinkovitosti in uspešnost, je prav, da izboljšamo dejavnike, ki vplivajo na učinkovitost in uspešnost, zato jih moramo poznati. Ker več aktivnosti institucije in menedžmenta vpliva na učinkovitost in uspešnost, jih imenujemo dejavniki uspešnosti in učinkovitosti. Kot temelj analize obremenjenosti so bili upoštevani (Andoljšek, 2004, str. 263):

- tehnično-tehnološki dejavniki, ki izražajo tehnično opremljenost,

- človeški dejavniki, ki izražajo znanje, sposobnost in motivacijo zaposlenih,

- organizacijski dejavniki, ki izražajo upravljanje in koordinacijo,

- kakovost, ki izraža kakovost storitev, ki si jo želijo uporabniki,

- $\quad$ izid, ki izraža izpolnjevanje poslanstva oz. smotra delovanja javne institucije.

Zaradi pomanjkanja ustreznih podatkov je bilo storjeno dvoje, prvič - oblikovan in obdelan je bil poseben vprašalnik za zaposlene o obsegu, zahtevnosti, pogostnosti in vsebini del, ki jih opravljajo ${ }^{\mathbf{1 5}}$, in drugič - razvita je bila posebna metodologija o ponderiranju in interpretaciji podatkov. Seveda pa je verodostojnost rezultatov odvisna od resničnosti vhodnih podatkov, ki bi jih kazalo $v$ nadaljevanju preveriti, objektivizirati oz. standardizirati (poenotiti). Metoda nam omogoča odkrivanje večjih anomalij pri obremenjenosti, ne more pa nadomestiti menedžerjevih izkušenj in občutkov.

15 Odgovori na vprašalnik s strukturirano tabelo so bili pri nekaj zaposlenih neuporabni, ker so bili presplošni, večina pa se je potrudila in odgovorila tako, da je bila možna vsaj minimalna obdelava. 
Kovač, Rakar, Andoljšek, Grošelj

Reorganizacija občinske uprave - primer Nove Gorice

Bistvene spremenljivke pri ocenjevanju obremenjenosti zaposlenih so bile 1- pogostost izvajanja določene naloge, 2- težavnost naloge in ocena 3- trajanja naloge. Na podlagi analize smo ugotovili, da delovni mesti direktorice občinske uprave in načelnika oddelka za splošne zadeve odstopata od povprečja navzgor in se kažeta kot najbolj obremenjeni delovni mesti. $V$ drugem kariernem razredu velja uravnoteženost. $\vee$ negativnem smislu pa $\vee$ prvem in drugem kariernem razredu odstopata dve delovni mesti $\vee$ oddelku za splošne zadeve, pri katerih pa je treba upoštevati posebnosti opisa del in nalog, saj sta mesti po vsebini nujni, čeprav izkazane obremenitve niso uravnotežene. Podrobnejši popis nalog, natančnejša opredelitev trajanja in težavnosti bi omogočili bolj realno ugotovitev dejanskega stanja. Pridobljena analitika sicer zadosti zahtevam, ki so bile postavljene, vendar pa kljub temu ostajajo odprta vprašanja, ki se bodo lahko reševala šele sproti ob uporabi metodologije. Predvsem je treba upoštevati, da so porabljeni čas za tipična dela in naloge določali zaposleni, kar je zato verjetno subjektivno ocenjeno.

\section{Predlogi izboljšav organizacije in poslovanja mestne uprave}

$\mathrm{Na}$ podlagi navedenih analiz in ugotovitev smo predlagali kopico sprememb, kjer smo upoštevali vsebino nalog mestne občine in njene uprave, dejansko izvajanje le-teh ter funkcionalni vidik vrste dela oz. delovnih operacij (de/centralizacijo ključnih podpornih nalog). Slednje izhodišče je temelj za združitev določenih vrst nalog in pomik bližje središču dejanskega upravljanja občinske uprave, tj. direktorju mestne uprave, zlasti pravno pomoč in svetovanje, kadrovske zadeve, poslovanje z dokumentarnim gradivom in nadzor evidentiranja dejansko izvajanih nalog.

Predlagali smo naslednje izboljšave:

- reorganizacijo oddelkov (zmanjšanje števila oddelkov, združitev skupnih služb) - ob opisu vsebinskih sprememb smo pripravili tudi nomotehnično ustrezna akta o spremembi odloka (mestnega sveta) o notranji organizaciji in pravilnika (župana) o sistemizaciji delovnih mest $\checkmark$ upravi,

- prerazporeditev skupnih (režijskih) nalog $\vee$ druge oddelke,

- premestitev posameznih delovnih mest $v$ druge oddelke,

- sprotno spremljanje obremenjenosti delovnih mest ter učinkovitosti in uspešnosti MONG pri doseganju ciljev in drugi vsebinski predlogi. 


\section{Slika 1: Predlogi neposredne reorganizacije}

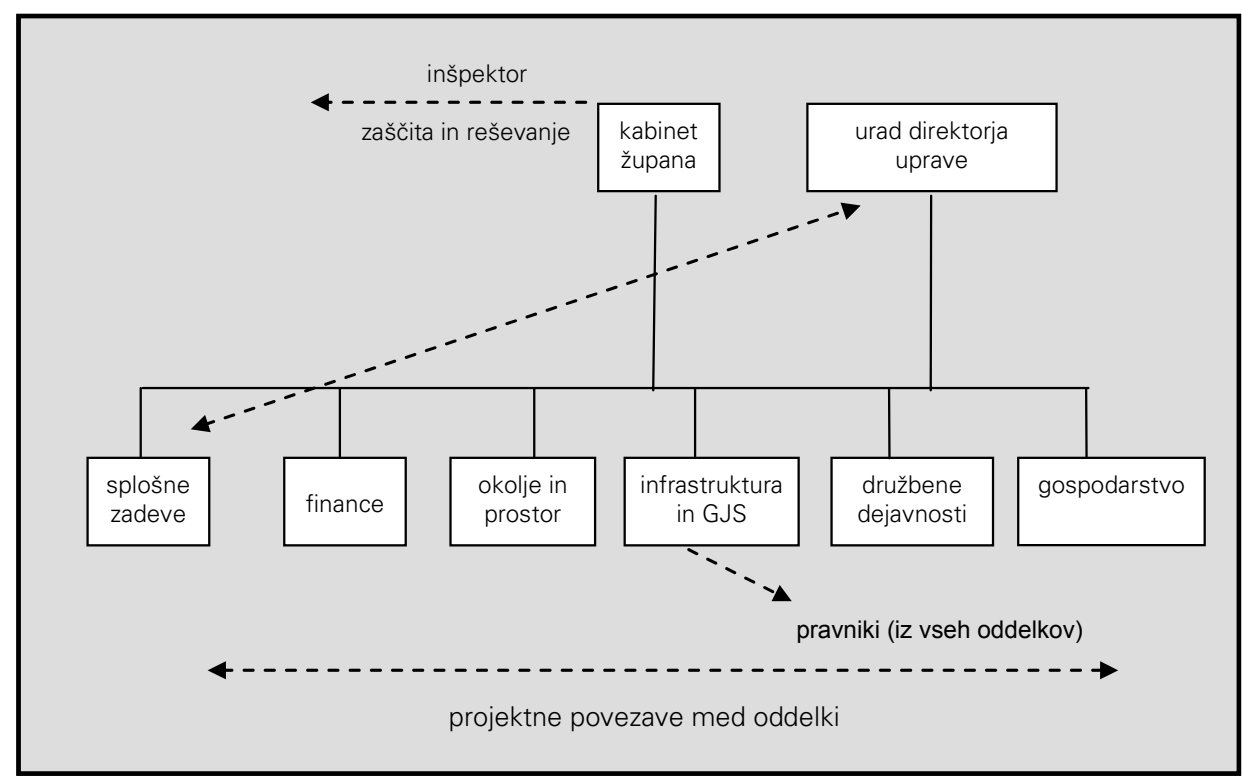

Pri predlogu reorganizacije smo upoštevali poleg omenjenih izhodišč predvsem analizo obremenjenosti, tako da bi bili oddelki uravnoteženi tudi po tej plati. Ravno rezultati analize obremenjenosti so nas prepričali, da alternativna zamisel bolj radikalne racionalizacije s še večjim zmanjšanjem števila oddelkov in s tem srednjega menedžmenta ne bi bila optimalna (možno bi bilo denimo združevati oddelke oz. naloge oddelkov za finance, gospodarstvo itd.).

Glede prerazporeditve posameznih služb smo predlagali predvsem vzpostavitev pravne službe $v$ uradu direktorja uprave ter centralizacijo ravnanja $z$ dokumentarnim gradivom $v$ uradu direktorice $s$ hkratno decentralizacijo operativnega poslovanja (torej polno izkoriščenostjo obstoječega informacijskega sistema Lotus Notes). Prerazporeditev posameznih delovnih mest je temeljila na resornem principu, saj denimo (apolitični) inšpektor po naravi stvari ne sodi $\checkmark$ (politični) kabinet župana. Spremljanje obremenjenosti in uspešnosti pa je ob predhodni vzpostavitvi kazalnikov in meril nujno za optimalnejšo izrabo delovnega časa, učinkovitost izrabe proizvodnih dejavnikov ter določanje ciljev MONG in njene uprave in doseganja le-teh. Zato smo predlagali, da se pri pripravi naslednjega proračuna opredeli cilje za dejavnosti in projekte ter vzpostavi stimulacijske (nefinančne) mehanizme za zaposlene odvisno od individualne obremenitve in učinkovitosti oz. uspešnosti. Hkrati smo predlagali še nekaj posameznih ukrepov, od odprave manjših pomanjkljivost $v$ zvezi s sistemizacijo delovnih mest glede na veljavno uredbo, do nadaljevanja zastavljenih projektov 
Kovač, Rakar, Andoljšek, Grošelj

Reorganizacija občinske uprave - primer Nove Gorice

(ugotavljanje zadovoljstva zaposlenih, letni razgovori) in vzpostavitev novih (ugotavljanje zadovoljstva strank).

Projektna skupina je svoj mandat s predlogi izboljšav zaključila. Načrtovanje in izvedba ter evalvacija predlaganih izboljšav, tako kot temeljna odprava nekaterih manjših kršitev predpisov, pa je $\vee$ pristojnosti vodstva uprave, župana in končno mestnega sveta.

\section{Metodološke izkušnje in priporočila}

Z vidika članov svetovalne skupine ugotavljamo, da smo pri opisanem projektu dosegli zastavljeni cilj, saj smo z različnimi analizami prišli do identičnih oz. prekrivajočih se predlogov ukrepov za racionalizacijo in siceršnje izboljšave poslovanja uprave MONG. $\vee$ podobnih nadaljnjih projektih bi sistematičen interdisciplinarni pristop vsekakor ohranili. Prav tako ocenjujemo kot pozitivno, da izvajalec (zunanji svetovalec) poda več alternativnih rešitev, če so te seveda možne, saj ima tako naročnik (uprava) več izbire za ukrepanje glede na posebnosti lokalnega okolja.

$\checkmark$ našem projektu smo $z$ vidika metodologije uporabili več izvirnih elementov, kjer največ pozornosti zasluži metodologija za analizo obremenjenosti oddelkov in tipičnih delovnih mest občinske uprave (tj. zasedenih mest po sistemizaciji glede na opis del in nalog ter hierarhični nivo, (npr. nazivi pri uradnikih). Dodatno gre opozoriti na po našem vedenju prvo zunanjo oceno javne organizacije po modelu CAF.

Bistvene spremenljivke pri ocenjevanju obremenjenosti zaposlenih so bile pogostost izvajanja določene naloge, težavnost naloge in ocena trajanja naloge. Ker naloge, kot tudi delovna mesta, na katerih se izvajajo določene naloge, niso enako zahtevne, smo primerljivost porabljenega časa za različno zahtevne naloge dosegli z izračunom enakovrednih števil - pogojnih enot. Pogojne enote smo določili kot produkt trajanja posamezne naloge in težavnosti posamezne naloge. Merska lestvica za težavnost je bila opredeljena od 1-5 in sicer od 1najbolj težko do 5 - najmanj težko. Zaradi enostavnosti raziskave smo predvideli linearni vpliv težavnosti na porabo časa, zato smo kot faktorje upoštevali mersko lestvico $v$ obratnem vrstnem redu (5 - najbolj težavna, 1 - najmanj težavna opravila). Ker zaposleni niso $v$ celoti ocenili celotnega delovnega časa, skupno število pogojnih enot ni neposredno primerljivo med delovnimi mesti. To pomanjkljivost smo odpravili s predpostavko, da delavec preostali neocenjeni delovni čas porablja tako kot ocenjeni delovni čas. Zato smo opredelili mero "število PE na delovni mesec". Ta mera omogoča primerjavo obremenjenosti delovnih mest. $V$ kolikor število PE na enoto efektivnega delovnega 
časa pomnožimo z delovnimi urami na mesec, dobimo podatek, koliko PE je bilo ustvarjenih $v$ mesecu na določenem delovnem mestu. Poleg tega smo med seboj primerjali le podobna delovna mesta oziroma zaposlene na delovnih mestih, za katere se po sistematizaciji zahteva podobna izobrazba oz. količnik plače, ki izraža zahtevnost delovnega mesta, izobrazbe in težavnost nalog. Glede na povedano smo na podlagi količnika plače za sistematizirana delovna mesta tvorili skupine primerljivih delovnih mest, ki sovpadajo s kariernimi razredi.

Kot posebno metodološko dodano vrednost bi želeli izpostaviti za naročnika izjemno pregledno podajo ugotovitev in predlogov, ki temelji na preprostem načelu t.i. semaforskih luči. Pri tem besedilo, označeno z rdečo, označuje, kaj mora organizacija spremeniti takoj in je zelo pomembno (npr. neusklajenost s predpisi), z rumeno je označeno, kar je pomembno, a ni potrebna takojšnja sanacija ali pa gre za srednjo stopnjo pomena zadeve, medtem ko zelena luč poudarja, kaj naj organizacija ohranja kot lastnosti, ki jo dvigujejo nad povprečje. Barve torej kažejo urgentnost in težo ukrepanja, kjer ima največjo prednost pomembno in nujno, nato sledi pomembno, a manj nujno in končno nujno, a manj pomembno ${ }^{\mathbf{1 6}}$.

Korak napredka v metodologiji bi bil, da bi različni specializirani svetovalci ${ }^{\mathbf{1 7}}$ združili izkušnje in po principu sinergije oblikovali model optimalne (re)organizacije različnih tipov in velikosti uprav lokalnih skupnosti.

$\checkmark$ neposredni povezavi s projektom pa bi kazalo razmisliti zlasti o treh bolj ali manj spornih metodoloških pristopih oz. virih, ki pa pretežno sodijo v polje pristojnosti nosilcev državnega in lokalnega upravnega sistema:

- pri primerjavi ekonomskih kazalnikov (mestnih) občin, kjer so obstoječe analize, podatke in razvrstitve glede na vir zajemanja podatkov lahko kot izhodišče vprašljive, smo rešitve že podali v zadnjem odstavku podpoglavja 2.1,

- glede na opredelitev modela CAF kot samoocenjevalne metode se poraja vprašanje, ali je zunanja ocena optimalna z vidika verodostojnosti rezultatov in doseganja učinkov,

- $\quad$ v zvezi z analizo zadovoljstva zaposlenih pa je po našem mnenju nujno opozoriti na potrebo po 1- upoštevanju ugotovitev in ukrepanju ter 2- kontinuiranem izvajanju tovrstne in podobnih analiz (zlasti še analiza zadovoljstva strank).

16 Naročnik, zlasti občinski funkcionarji, z vidika lastnega (političnega) programa seveda določene elemente lahko vidijo $v$ drugačnem prioritetnem redu in jih pač razvrstijo na novo. $17 \mathrm{~V}$ letih 2004/5 je npr. podoben projekt reorganizacije in racionalizacije občinske uprave vršila projektna skupina Pravne fakultete Univerze v Mariboru v eni izmed mestnih občin, prav tako je nekaj (mestnih in drugih) občin razvijalo lastne sisteme s pomočjo zasebnih svetovalcev, tudi v okviru pridobitve certifikata ISO. 
Kovač, Rakar, Andoljšek, Grošelj

\section{Reorganizacija občinske uprave - primer Nove Gorice}

\section{Zaključek}

V Sloveniji smo imeli ob preoblikovanju t. i. komunalnih občin od I. $1995 \mathrm{z}$ ločitvijo na dvotirni sistem državne uprave in lokalne samouprave najprej 147 občin, danes 193, od tega 11 mestnih. Občine niso prepuščene same sebi, saj jim tako in drugače pomaga država (danes pretežno prek Službe Vlade RS za lokalno samoupravo in regionalno politiko in Ministrstva RS za finance), vendar pa so avtonomen in svojemu prebivalstvu odgovoren subjekt. Zato se čedalje več vodilnih $v$ občinskih strukturah, seveda tudi pod pritiski javnosti, medijev, političnih strank, gospodarstva idr., zavestno odloča za sistemske izboljšave v poslovanju, najprej v upravi v ožjem pomenu besede in širše pri izvajalcih lokalnih javnih služb. Pri tem ni bistveno, ali se bodo pristojni naslonili na lastne sile ali zunanje svetovalce, čeprav je nesporno optimalen kombinirani pristop.

Da bi se izboljšali, moramo vedeti, kam želimo in kje smo. Stalne izboljšave pa niso nujne le $v$ organizacijah, ki stremijo $k$ dobičku, temveč tudi v tistih organizacijah, ki poslujejo $v$ javnem interesu in $z$ davkoplačevalskim denarjem. Zato mora postati stremenje $k$ racionalizaciji ob predhodnem upoštevanju izpolnjevanja ciljev in pravil ter nenazadnje predvolilnih obljub ne le lastnost najboljših, ampak standard družbeno in etično odgovornih posameznikov in organizacij.

Dr. Polona Kovač, univerzitetna diplomirana pravnica in magistrica politologije, je višja predavateljica na Fakulteti za upravo, kjer se je zaposlila I. 2002 po predhodnem delu v državni upravi. Pedagoško in raziskovalno se ukvarja z novim javnim menedžmentom, reformo javne uprave, pravno ureditvijo uprave, upravnimi postopki in kakovostjo v javnem sektorju.

Dr. Žiga Andoljšek je doktoriral s področja merjenja uspešnosti v državni upravi. Zaposlen je na Ministrstvu za finance ter predava na Fakulteti za upravo v Ljubljani. Na Ministrstvu za finance vodi Direktorat za javno premoženje. Raziskovalno se ukvarja s kvantitativnim ugotavljanjem učinkovitosti in uspešnosti v javnem sektorju.

Mag. Iztok Rakar je diplomiral in magistriral na Pravni fakulteti v Ljubljani. Po opravljenem sodniškem pripravništvu na Višjem sodišču v Ljubljani se je leta 2000 zaposlil kot asistent na Fakulteti za upravo, kjer se ukvarja predvsem s pravno ureditvijo javne uprave in širšega javnega sektorja.

Barbara Grošelj, diplomirana upravna organizatorka in vpisana na specialistični študij Javna uprava. Diplomirala je s področja primerjalne analize e-portalov in študij zaključila kot najboljša diplomantka dodiplomskega programa. Zaposlena je na Fakulteti za upravo kot strokovna delavka za znanstveno-raziskovalno dejavnost in objavlja strokovne prispevke na konferencah s področja informatike. 


\section{Literatura in viri}

- $\quad$ Andoljšek, Ž. (2004): Dejavniki vplivanja na učinkovitost in uspešnost v organizacijah javne uprave, Javna uprava, Ljubljana, str. 257-278.

- $\quad$ Crnica, S. (2005): Novogoriška mestna uprava - je preveč potratna, Delo, 5. 3. 2005, str. 6.

- Ivanko, Š. (2000): Strukture in procesi v organizaciji, Visoka upravna šola, Ljubljana.

- Kadrovski načrt za leti 2004/2005 in 2005/2006, interni vir, Mestna občina Nova Gorica.

- Katalog pristojnosti, http://www.lexlocalis.info/KatalogPristojnosti/SeznamMap.aspx?SectionID=999f3a8e-3a93-4cf1-a1f0-82780155d7e8, dobljeno junija 2005.

- Kovač, P. (2002): Evropski model - Skupni ocenjevalni okvir za organizacije v javnem sektorju (CAF), Od ideje o kakovosti do dobrih praks v javni upravi, Ljubljana.

- Kovač, P., Andoljšek, Ž., Rakar. I., Grošelj, B. (2005): Zaključno poročilo o analizi organiziranosti uprave Mestne občine Nova Gorica, Fakulteta za upravo, Ljubljana.

- Mestna občina Nova Gorica, http://www.nova-gorica.si/, dobljeno junija 2005.

- Ministrstvo za javno upravo, http://www.mju.gov.si/, dobljeno junija 2005.

- Odlok o organizaciji in delovnem področju občinske uprave Mestne občine Nova Gorica z dne 24. 4. 2003.

- Odlok o proračunu Mestne občine Nova Gorica za leto 2005, http://www.novagorica.si/finance/finance_proracun_odlok.pdf, dobljeno junija 2005.

- Peters, B. G., Pierre, J. (2003): Handbook of Public Administration, SAGE Publications, London, Thousand Oakes, New Delhi.

- Pravilnik o sistemizaciji delovnih mest v upravi Mestne občine Nova Gorica (neuradno prečiščeno besedilo tekstualnega dela pravilnika) z dne 29. 5. 2003 in 30. 3. 2005.

- Priprava strateškega dokumenta uvajanja elektronskega poslovanja v lokalne skupnosti (e-občina),

http://mid.gov.si/mid/mid.nsf/f1?OpenFrameSet\&Frame=main\&Src=/mid/mid.nsf/0/8D1 0EB467CDD6069C1256C53003E6EBC?OpenDocument, dobljeno junija 2005.

- Proračun Mestne občine Nova Gorica za leto 2005 - Področne tabele, http://www.novagorica.si/finance/finance_proracun_podrocne_tabele.xls«, dobljeno junija 2005.

- Pusić, E. (2002): Nauka o upravi (12. izmijenjeno i dop. izd.), Školska knjiga, Zagreb.

- Schuppert, G. F. (2000): Verwaltungswissenschaft. Nomos, Baden-Baden.

- Snoj et al. (1999): Merjenje zaznane kakovosti družbe ISS. Akademija MM, str. 33-41.

- Staes, P., Thijs, N. (2005): Quality Management on the European Agenda, Eipascope, Nr. 2005/1, str. 33-41. 
Kovač, Rakar, Andoljšek, Grošelj

Reorganizacija občinske uprave - primer Nove Gorice

- Statut Mestne občine Nova Gorica,

http://193.77.181.72:8080/mma.nsf/OC/050516144736E/\$file/dato3_statut_86a.pdf, dobljeno junija 2005.

- Šmidovnik, J. (1995): Lokalna samouprava. Cankarjeva založba, Ljubljana.

- Virant, G. (1998): Pravna ureditev javne uprave, Visoka upravna šola, Ljubljana.

- Vlaj, S. (2004): Lokalna samouprava: teorija in praksa, Fakulteta za upravo, Ljubljana.

- Zakon o lokalni samoupravi (ZLS), Ur. I. RS št. 72/1993, 6/1994 OdI.US: U-I-13/94-65, 45/1994 Odl.US: U-I-144/94-18, 57/1994, 14/1995, 20/1995 OdI.US: U-I-285/94-105, 63/1995, 73/1995 Odl.US: U-I-304/94-9, 9/1996 Odl.US: U-I-264/95-7, 39/1996 Odl.US: U-I-274-95, 44/1996 OdI.US: U-I-98/95, 26/1997, 70/1997, 10/1998, 68/1998 Odl.US: U-I39/95, 74/1998, 12/1999 Skl.US: U-I-4/99, 36/1999 Odl.US: U-I-313/96, 59/1999 Odl.US: U-I-4/99, 70/2000, 94/2000 SkI.US: U-I-305-98-14, 100/2000 SkI.US: U-I-186/00-10, 28/2001 Odl.US: U-I-416/98-38, 87/2001, 16/2002 SkI.US: U-I-33/02-7, 51/2002, 108/2003 Odl.US: U-I-186/00-21, 77/2004 OdI.US: U-I-111/04-21. 


\section{Municipal administration reorganisation - the case of the Nova Gorica Municipality}

For the purpose of an effective improvement of its work and taking into account the legalities involved, in March 2005 the Nova Gorica Municipality established contacts with the Faculty of Public Administration with the aim of preparing a project assignment entitled "The analysis of the Nova Gorica Municipality Organisation". The assignment comprised both an analysis of organisation and workload by individual organisational units and typical work places in the Nova Gorica Municipality administration on the one hand, and proposals for internal organisational changes on the other. The client's primary wish was to obtain data on the workload of departments and work places and to design an organisation in such a manner that would make the workload relatively even. An analysis and improvement of the work atmosphere and the organisational climate in administration were also of particular importance.

The main aim of this paper is to present to the public the approaches to the project in question: an analysis of the situation with identified opportunities for and obstacles to improvement; proposals for the improvement of organisation and municipal administration; methodological experience and conclusions. The approach to the project was oriented towards an integrated study of legal, economic, informational and organisational aspects. It is very important that no one of these aspects is particularly emphasised nor neglected. The project group obtained information which was later processed from numerous sources and focused on the internal material of the Nova Gorica Municipality, its own studies, Internet sources and expert literature. The project group chose an interdisciplinary approach for the performance of the task which includes the following sets of analyses: an analysis of economic indicators, a legal analysis of powers and the organisational structure of municipal administration, a comprehensive analysis of administration performance according to the European self-assessment business excellence model for public sector organisations (CAF), an analysis of administration employee satisfaction, a comparative analysis of economic indicators and the organisation of other municipalities, and a workload analysis of departments and typical workplaces. 
Kovač, Rakar, Andoljšek, Grošelj

Reorganizacija občinske uprave - primer Nove Gorice

Economic indicators are presented within the framework of the situation analysis. The analysis comprised the economy of municipal administration operations, total expenditure for administration which includes employee expenditure and other current expenditure. Indicators which also have to be taken into account include current employee expenditure, per capita income and per capita expenditure. Cumulative indicators, expenditure indicators and time series were likewise analyzed. The results of the analysis have shown that it is possible to improve the organisation in terms of rationalization and a more even distribution of tasks. The comparative overview of municipal administration in the municipalities of Kranj, Murska Sobota, Velenje and Novo mesto and the analysis of their organisational structure shows that the Nova Gorica Municipality ranks in the middle in terms of various indicators (e.g. the number of departments, even distribution of the number of employees and workplaces by department).

Presented in the framework of the legal analysis are the theoretical premises regarding the functions and tasks of self-governing local communities, especially municipalities, the evaluation of the extent and types of the performed tasks and the legal analysis of the existing internal organisation and classification of posts.

The analysis based on the CAF model as a tool for the overview of the situation in a given organisation, which presents opportunities for improvement and represents a successful model for organisational improvement, has provided results which reflect the Slovenian average. The assessment has shown that the role of the municipality is highly favourable in terms of its impact on society and the environment, with employees willing to assume additional workload and responsibilities.

57 employees (approximately $70 \%$ ) responded to the survey on employee satisfaction. The project group has thus obtained statistically reliable information which reflect a true and fair picture of employee satisfaction. Due to the fact that the survey was anonymous, the results were far more satisfactory and individual. The comparison of the Nova Gorica Municipality with other administrative units has shown similar workload, stimulation and the significance of professional competence and objectives supported by the administration; the Nova Gorica Municipality stands out when it comes to the willingness of employees to contribute to the welfare of the local social environment. 
Once the analysis was concluded, the project group adopted some concrete proposals for reorganisation in terms of improvement and successful work. Changes relate to the reorganisation of departments, transfer of certain workplaces to other departments, redistribution of joint tasks to other departments, content-driven proposals and constant monitoring of workplace workload, and the efficiency and performance of the Nova Gorica Municipality in achieving its objectives. The baselines which are important for an effective change of municipal administration operation on the basis of an altered organisational scheme include the adequate setting of objectives under the responsibility of the Head of administration. With their knowledge, competences and skill, these heads contribute significantly to employees contributing more to improved departmental effectiveness, better results, motivation and the general level of satisfaction.

Finally, the paper draws attention to the original solutions which were developed by the Faculty of Public Administration project group within the framework of the research and which relate mainly to the workload analysis, the general assessment of the organisation's performance and the interdisciplinary nature of approaches (economic, organisational, legal and other aspects). 